\title{
Carbono orgânico, óxidos de ferro e distribuição de agregados em dois solos derivados de basalto no Rio Grande do Sul - Brasil
}

\author{
Organic carbon , iron oxides and aggregate distribution in two basaltic soils from Rio Grande do Sul \\ State-Brasil
}

\author{
Fernando Perobelli Ferreira' ${ }^{I}$ Antonio Carlos de Azevedo ${ }^{I I}$ Ricardo Simão Diniz Dalmolin ${ }^{\text {II }}$ \\ Darian Girelli ${ }^{\text {II }}$
}

RESUMO

Vários atributos do solo são capazes de afetar o comportamento de sua estrutura. Dentre eles, o conteúdo de carbono orgânico (CO) do solo e tanto o conteúdo quanto os tipos de óxidos de ferro têm sido relacionados como os mais importantes. Desta forma, o presente trabalho foi desenvolvido visando a avaliar o comportamento de agregados do solo em relação a estes agentes, em solos de uma área de agricultura familiar no Rebordo do Planalto, situado entre o Planalto Médio e a Depressão Central do Estado do Rio Grande do Sul. Agregados menores que $8 \mathrm{~mm}$ foram obtidos de um Argissolo Vermelho-Amarelo e de um Neossolo Litólico, ambos sob floresta, pastagem e lavoura, e submetidos à agitação em água. Depois de agitados durante 0, 30, 60 e 90min, foram determinadas a distribuição de agregados em três classes de tamanho e a concentração de carbono orgânico (CO), ferro extraível com ditionito-citrato-bicarbonato ( $\mathrm{Fe}$ ) e oxalato de amônio ( $\mathrm{Fe}_{\mathrm{o}}$ ) nos agregados. O Neossolo apresentou maior teor de CO em relação ao Argissolo, independentemente do tipo de uso, e o uso floresta apresentou o maior e o uso lavoura o menor teor de CO no solo, independentemente do tipo de uso do solo. Os teores de $\mathrm{Fe}_{d}$ e $\mathrm{Fe}$ do solo foram similares entre os solos e entre os usos em cada solo. Os solos estudados apresentaram hierarquia de agregados (HA) em grau diferenciado, sendo que os agregados mais estáveis (90min de agitação) apresentaram uma leve tendência a possuírem mais carbono em relação aos menos estáveis (0min de agitação). Dentre as variáveis medidas neste estudo, o teor de CO do solo foi o atributo que mais afetou a expressão da HA. Além disso, os resultados indicaram que a ação dos óxidos de Fe na agregação depende não somente de seus teores e tipos, mas também dos teores de CO existentes nos solos. Ainda assim, observou-se que os agregados mais estáveis tenderam a apresentar maiores teores de $\mathrm{Fe}_{d}$ e menores de $\mathrm{Fe}_{0}$.

Palavras-chave: agentes estabilizantes, hierarquia de agregados, estrutura do solo.

\begin{abstract}
Several factors can affect the behavior of soil structure. Amongst them, the organic carbon (OC) content and the content and type of iron oxides present in the soil have been related as the most important. This study is aimed at evaluating soil aggregate behavior regarding to the role of organic carbon, and forms of iron oxides in two soils developed from basalt in subtropical Brazil. Aggregates with size less than $8 \mathrm{~mm}$ of an Udorthents and a Paleudult under forest, pasture and conventional tillage of the steep backslope of Sul Riograndense plateau were shaked in water during 0,30, 60 and 90 minutes. The aggregate distribution in three size classes was measured as well as the content of OC, iron extractable with ditionite-citrate-bicarbonate $\left(\mathrm{Fe}_{d}\right)$ and ammonium oxalate $(\mathrm{Fe})$ in the aggregates. The Udorthents showed greater content of soil OC than Paleodult and the forest soil showed greater content of soil OC than pasture and conventional tillage. The content of $\mathrm{Fe}_{d}$ and $\mathrm{Fe}$ were similar between both soils and uses. The studied soils showed a differentiated degree of aggregate hierarchy $(\mathrm{AH})$. The most stable aggregates (90min of shaking) presented a trend to possess greater content of $\mathrm{OC}$ than the less stable ones (Omin of shaking). Amongst the variables considered in this study, the content of OC was the attribute that more affects the expression of $\mathrm{AH}$ and the action of iron oxides in the aggregation not only depends on its type and amount, but also of the content of soil OC. It was also observed that the most stable aggregates (90min of shaking) tended to present greater content of $\mathrm{Fe}_{d}$ and smaller content of $\mathrm{Fe}_{0}$.
\end{abstract}

Key words: stabilizing agents, aggregate hierarchy, soil structure.

\section{INTRODUÇÃO}

A gênese da estrutura do solo se refere às causas e aos mecanismos envolvidos na formação e

IPrograma de Pós-graduação em Agronomia, Solos e Nutrição de Plantas, Escola Superior de Agricultura Luiz de Queiroz, Universidade de São Paulo (ESALQ, USP). Av. Pádua Dias, 11, CP 9, 13418-900, Piracicaba, SP, Brasil. Email: perobff@esalq.usp.br IIDepartamento de Solos, Centro de Ciências Rurais (CCR), Prédio 42, Universidade Federal de Santa Maria (UFSM). Av. Roraima, 1000, 97119-900, Santa Maria, RS, Brasil. *Autor para correspondência. 
estabilização das unidades estruturais do solo. Os fatores que afetam sua gênese são: (1) a pedogênese e o intemperismo de minerais, (2) a floculação e os cátions trocáveis, (3) os ciclos de umedecimento e secagem, (4) o teor e o tipo de argila, (5) o carbono orgânico do solo (COS), (6) os óxidos de ferro e de alumínio, e (7) a ação das plantas e dos organismos do solo, sendo que a COS e os óxidos de ferro são tidos como os principais agentes atuantes (BAVER et al., 1972; BUOL et al., 1997; HILLEL, 1998; BRONICK \& LAL, 2005).

A ordem hierárquica na formação dos agregados do solo começa pela união de partículas individuais, formando um domínio de argila, que, por sua vez, unem-se formando microagregados $(=0,250$ $\mathrm{mm})$ e assim sucessivamente até a formação dos macroagregados (>0,250mm) (HADAS, 1987). Combase nisso, DEXTER (1988) discutiu o comportamento dos agregados do solo em relação à hierarquia e OADES \& WATERS (1991) comprovaram a sua existência, exceto para Oxisols, nos quais os óxidos de ferro são os principais responsáveis pela formação e estabilização estrutural do solo. SIX et al.(2000) também verificaram menor expressão da hierarquia de agregados em solos cauliníticos e com presença de óxidos de ferro. O conceito de hierarquia de agregados (HA) implica então que, partindo da aglutinação de partículas primárias do solo (areia, silte e argila) pequenos agregados são formados e estes, por sua vez, formam agregados sucessivamente maiores, constituindo-se cada um destes estágios de agregação em um nível hierárquico.

A hierarquia de agregados tem sido utilizada em diversos estudos para explicar as relações existentes entre os agentes estabilizantes, principalmente COS, e a agregação do solo (ELLIOT, 1986). No entanto, apesar da existência de uma grande quantidade de estudos científicos sobre o assunto, são poucas as generalizações que podem ser realizadas sobre a estabilidade estrutural dos solos, pois tanto a estrutura do solo quanto os fatores que a afetam não podem ser idealizados como simples e estáticos.

Particularmente, na região de Vale Vêneto RS, classes de solos como os Neossolos e os Argissolos derivados de basalto alternam-se em pequenas distâncias (KLAMT et al., 1997), permitindo, desta forma, a comparação entre os efeitos dos usos do solo na estabilidade de agregados com uma mínima interferência da variação dos fatores regionais (precipitação, insolação, etc.).

Dessa forma, o presente trabalho tem por objetivo investigar as relações existentes entre o comportamento e a estabilidade dos agregados e seus principais agentes estabilizantes (carbono e óxidos de ferro), bem como as modificações ocasionadas na estrutura do solo por três diferentes tipos de uso em um Argissolo Vermelho-Amarelo e num Neossolo Litólico, derivados de basalto, na borda sul do Planalto Sul Riograndense.

\section{MATERIAL E MÉTODOS}

Este estudo foi realizado em Vale Vêneto (29³3’S, 5327’ W), distrito do município de São João do Polêsine, localizado no Rebordo do Planalto do RS. Os solos estudados foram classificados como Argissolo Vermelho-Amarelo Alumínico e Neossolo Litólico Eutrófico típico (EMBRAPA, 1999) e como Typic Paleodult e Typic Udorthents (SOIL SURVEY STAFF, 1994).

As amostras foram coletadas sob três diferentes tipos de uso: floresta, pastagem e lavoura, distantes aproximadamente 50 metros. As áreas de lavoura estavam sendo manejadas no sistema convencional, com uso de tração animal e rotação milho/ soja no verão e aveia/feijão no inverno, há aproximadamente 10 anos, e as áreas de pastagem foram instaladas, há aproximadamente 10 anos, sobre uma antiga lavoura de cana-de-açúcar. A floresta, secundária, tinha pelo menos 50 anos de estabelecimento.

Foram coletadas amostras do horizonte A dos solos nos diferentes tipos de uso para as análises químicas gerais. Para a determinação da distribuição de agregados, a amostragem foi realizada extraindo-se blocos indeformados de $30 \mathrm{~cm}$ de aresta do horizonte superficial dos solos nos diferentes usos, utilizandose metodologia descrita em KEMPER \& CHEPIL (1965).

A determinação da distribuição de agregados foi realizada com quatro alíquotas de $10 \mathrm{~g}$ de agregados menores que $8 \mathrm{~mm}$ em base de massa seca, colocados em frascos de vidro de $250 \mathrm{~mL}$ juntamente com $175 \mathrm{~mL}$ de água destilada e agitados horizontalmente a 100 oscilações $\mathrm{min}^{-1}$ e $10 \mathrm{~cm}$ de deslocamento durante 0, 30, 60 e 90min (uma alíquota para cada tempo de agitação). Após a agitação, procedeu-se ao peneiramento utilizando-se peneiras com malha de 2, 0,25 e 0,053mm, sendo que o material não agregado foi levemente lavado com água destilada do material agregado retido no conjunto de peneiras. $\mathrm{O}$ material agregado foi secado em estufa a $105^{\circ} \mathrm{C}$ durante $24 \mathrm{~h}$ e pesado. A fração areia em cada classe de tamanho foi determinada dispersando-se o material retido com $\mathrm{NaOH} \mathrm{N}$ e lavagem com jatos de água. Assim, admite-se que os grãos de areia contidos no interior dos agregados não foram retidos nas peneiras em cada classe de tamanho, sendo, portanto, a massa de areia descontada em cada classe constituída predominantemente de grãos simples (conforme 
KEMPER \& CHEPIL, 1965). A porcentagem de agregados (\% agregados) foi calculada através da equação (1):

$$
\%_{\text {agregados }}^{(i, t)}=\frac{\left(\left(B_{(i, t)}-C_{(i, t)}\right) * 100\right)}{D},
$$

em que: \% agregados $_{(i, t)}$ é a porcentagem de solo que ocorre como agregados na classe de tamanho i no tempo $\mathrm{t} ; B_{(i, t)}$ é a massa seca de material da classe de tamanho i no tempo t; $C_{(i, t)}$ é a massa seca da fração areia da classe de tamanho i no tempo t e $D$ é a massa seca inicial da amostra. As determinações foram realizadas em triplicatas e a obtenção de agregados para a realização das análises químicas $\left(\mathrm{CO}, \mathrm{Fe}_{\mathrm{d}}\right.$ e $\mathrm{Fe}$ ) foi realizada de maneira semelhante, porém sem separação da fração areia, sendo que os agregados foram secados em estufa a $50^{\circ} \mathrm{C}$.

Para as amostras de solo e as amostras das classes de agregados em cada tempo de agitação, determinou-se o teor de CO pelo método YEOMANS \& BREMNER (1988), adaptado por NELSON \& SOMMERS (1996).

A extração do ferro referente aos óxidos de ferro pedogênicos $\left(\mathrm{Fe}_{\mathrm{d}}\right)$ foi realizada através de uma modificação do método de extração de ferro DCB $_{80}$ (MEHRA \& JACKSON, 1960), adaptado à temperatura ambiente $\left(\mathrm{DCB}_{20}\right)$ por HOLMGREN (1967). Resumidamente, adicionou-se a 50mg de TFSA $10 \mathrm{~mL}$ da mistura de uma solução de Citrato-Na $0,3 \mathrm{~mol} \mathrm{~L}^{-1}$ : bicarbonato de sódio $1 \mathrm{~mol} \mathrm{~L}^{-1}$, na razão 8:1, em tubos de centrífuga de $15 \mathrm{~mL}$ de volume, os quais foram agitados por $16 \mathrm{~h}$ à temperatura ambiente. A extração do ferro referente aos óxidos de ferro pedogênicos de baixa cristalinidade $(\mathrm{Fe}$ ) foi realizada pelo procedimento de dissolução com oxalato de amônio $0,2 \mathrm{~mol} \mathrm{~L}^{-1} \mathrm{a}$ pH 3 e no escuro, segundo SCHWERTMANN (1964). Após as extrações, as amostras foram centrifugadas a 2000 RPM durante $5 \mathrm{~min}$, o extrato foi imediatamente coletado e a determinação dos teores de ferro foi realizada por espectroscopia de absorção atômica (EAA).

Como as determinações dos teores de CO foram realizadas na fração agregado+areia, para que se obtivesse os teores de CO referentes somente aos agregados de cada classe, foi realizada uma correção dos teores de CO obtidos em base da massa seca de agregados. Além disso, é possível que os extratores utilizados para solubilizar os óxidos de ferro pedogênicos solubilizem parte do ferro alocado em minerais primários como a magnetita, comum na fração areia destes solos. Assim, os teores de $\mathrm{Fe}_{\mathrm{d}}$ e de $\mathrm{Fe}$ o também foram determinados na fração areia de cada classe de agregados e descontados dos teores de $\mathrm{Fe}_{\mathrm{d}}$ e $\mathrm{Fe}_{0}$ obtidos na fração agregados+areia.
Os dados foram analisados em relação ao comportamento da \% agregados, dos teores de CO, $\mathrm{Fe}_{\mathrm{d}}$ e Fe nas classes de agregados, em função do tempo de agitação. Também foram realizadas análises de correlação de Pearson entre os teores de $\mathrm{CO}, \mathrm{Fe}_{\mathrm{d}}$ e Fe no solo e o nas classes de agregados, em função dos tempos de agitação; entre os teores de $\mathrm{CO}, \mathrm{Fe}_{\mathrm{d}}$ e $\mathrm{Fe}_{\mathrm{o}}$ do solo e a \% agregados, em função das diferentes classes de tamanho; e entre os teores de $\mathrm{CO}, \mathrm{Fe}_{\mathrm{d}}$ e $\mathrm{Fe}$ nas classes de agregados e a \% agregados, em função das classes de tamanho nos diferentes tempos de agitação. Somente as correlações significativas são apresentadas. Nos gráficos das figuras 1 e 2, os pontos não plotados se referem à inexistência de material suficiente na classe de tamanho do agregado após um determinado tempo de agitação.

\section{RESULTADOS E DISCUSSÃO}

Concentração de Carbono Orgânico (CO) e de Ferro $\left(\mathrm{Fe}_{\mathrm{d}}\right.$ e $\left.\mathrm{Fe} \mathrm{o}_{\mathrm{o}}\right)$ no solo.

O Neossolo apresentou maiores teores de CO (63,4, 46,4 e 36,4g kg-1 para os usos floresta, pastagem e lavoura, respectivamente) se comparado ao Argissolo (22,0, 13,5; e 11,7g kg-1 para os usos floresta, pastagem e lavoura, respectivamente), independentemente do tipo de uso. Além disso, a quantidade de CO foi decrescente da floresta para a pastagem e desta para a lavoura, em ambos os solos.

O Neossolo concentra a atividade biológica e acumula resíduos apenas no horizonte $\mathrm{A}$, já que não possui horizonte B. O uso floresta também acumula mais carbono devido ao maior aporte de resíduos de plantas na superfície, quer por uma maior produtividade da floresta, quer pela menor exportação de biomassa, se comparado aos usos lavoura e pastagem. Já no uso lavoura, o revolvimento do solo, além de expor os resíduos orgânicos aos microorganismos, também aumenta a aeração do solo, acelerando ainda mais o processo de decomposição da MOS (CARPENEDO \& MIELNICZUK, 1990).

Em relação aos teores e às formas de ferro no solo $\left(\mathrm{Fe}_{\mathrm{d}}\right.$ e $\left.\mathrm{Fe}_{\mathrm{o}}\right)$, exceto para o uso pastagem, observou-se que praticamente não ocorreram variações entre os usos no mesmo solo e entre os solos (57,8, 67 e 57,6g kg-1 de $\mathrm{Fe}_{\mathrm{d}}$ e 3,7, 2,7 e 3,6g kg-1 de Fe Neossolo sob floresta, pastagem e lavoura, respectivamente; e 66,8, 37,4 e 59,1 $\mathrm{g} \mathrm{kg}^{-1} \mathrm{de} \mathrm{Fe}_{\mathrm{d}}$ e 2,8, 2,4 e 3,4g kg-1 de $\mathrm{Fe}_{\mathrm{o}}$ para o Argissolo sob floresta, pastagem e lavoura, respectivamente). Os menores teores observados para o uso pastagem podem ter sido ocasionados pelos menores teores de argila nesse uso em ambos os solos (223, 190 e $280 \mathrm{~g} \mathrm{~kg}^{-1}$ para o Argissolo 


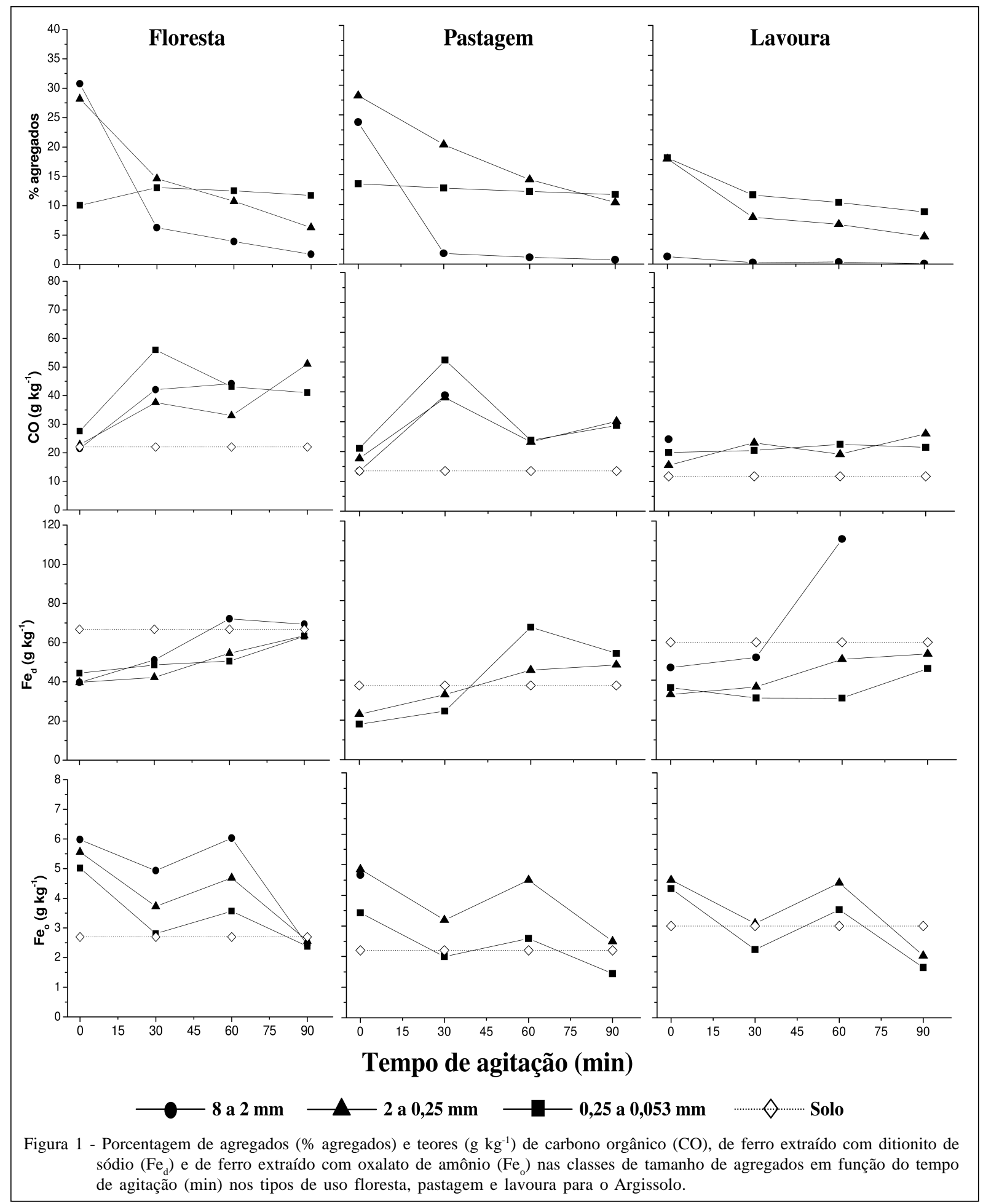

sob floresta, pastagem e lavoura, e 193, 160 e $200 \mathrm{~g} \mathrm{~kg}^{-1}$ para o Neossolo sob floresta, pastagem e lavoura, respectivamente). O menor teor de argila pode decorrer da ação de erosão diferencial ou seletiva, no uso atual ou pretérito dessa área.
Distribuição de agregados no solo

Nos solos onde existe HA, a aplicação de energia desagregante produz agregados menores. Em solos sem HA, a aplicação de energia gera partículas isoladas de areia, silte e argila (OADES \& WATERS, 


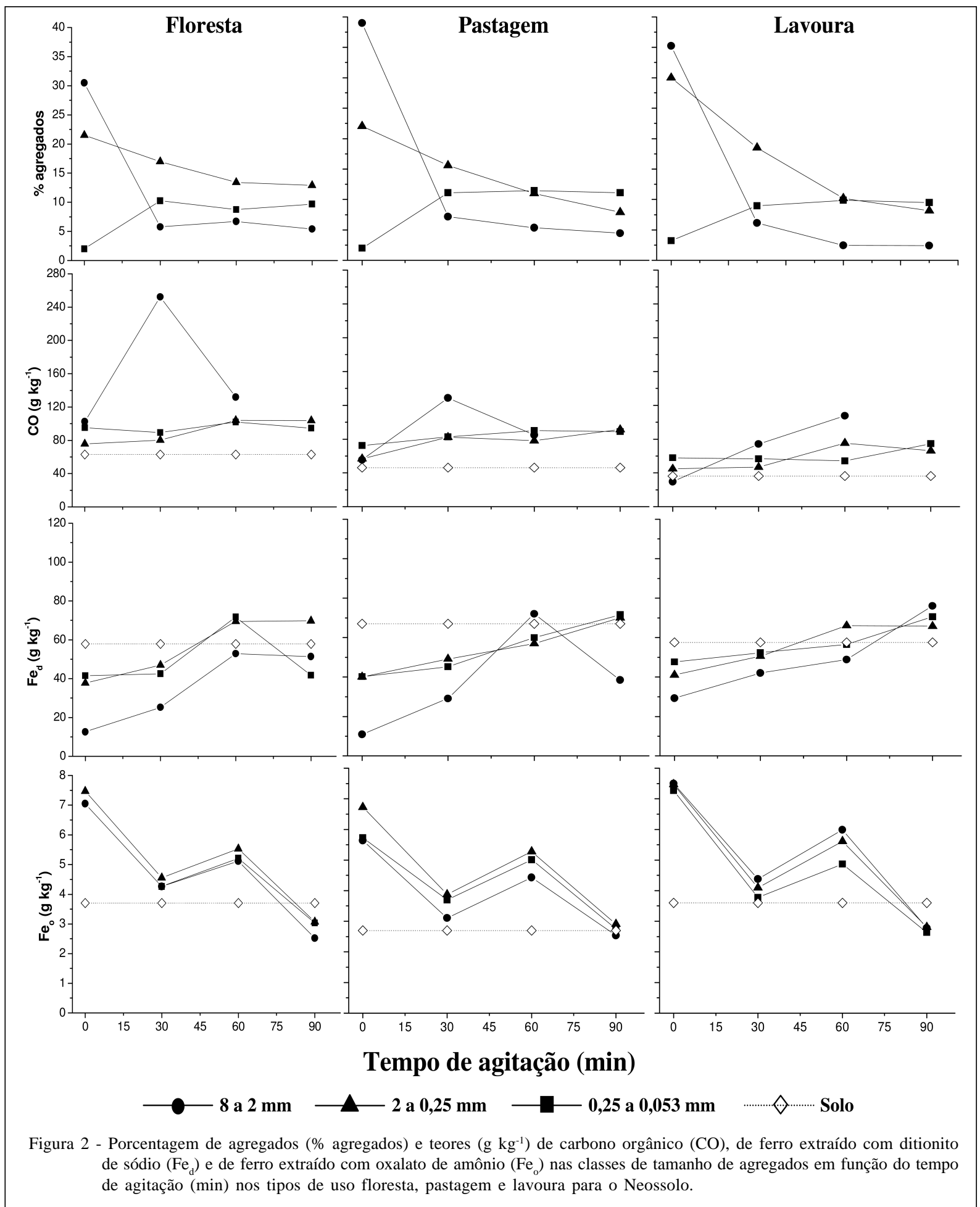

1991). A lógica empregada neste estudo para detecção de HA é conservadora, pois a HA foi detectada apenas nos casos onde “ $\mathrm{T}_{i}$ ” (taxa de desagregação de uma determinada classe “i”) fosse maior que " $\mathrm{P}_{\mathrm{i}}$ ” (taxa de aporte de agregados originados das classes superiores $\mathrm{i}+1, \mathrm{i}+2, \ldots, \mathrm{i}+\mathrm{n})$. Dessa forma, nas amostras analisadas, a HA foi detectada porque, nas curvas de desagregação obtidas (Figuras 1 e 2), a \% agregados nas classes de 8 
a $2 \mathrm{~mm}$ e de 2 a $0,25 \mathrm{~mm}$ diminuiu e a \% agregados na classe de 0,25 a 0,053mm aumentou com o aumento do tempo de agitação.

A maior expressão da HA ocorreu no Neossolo, pois foi verificada nos três usos (floresta, pastagem e lavoura), enquanto que, no Argissolo, foi verificada somente no uso floresta. Isso provavelmente se deve ao maior teor de CO no Neossolo em relação ao Argissolo, concordando com OADES \& WATERS (1991) e SIX et al. (2000) sobre o papel do CO na expressão da HA nos solos. Reforçando esse resultado, observou-se ainda uma maior \% agregados na classe de 8 a 2mm, no tempo 0min de agitação, para as amostras com maior teor de $\mathrm{CO}$, o que coincidiu com uma pequena \% agregados na classe de 0,25 a $0,053 \mathrm{~mm}$ e com uma correlação significativa e negativa entre o teor de CO do solo e a \% agregados nesta classe e neste tempo $(-0,905 ; \mathrm{p}<0,05 ; \mathrm{n}=6)$. Esses agregados pequenos começaram a ser liberados após 30 minutos de agitação.

Essa dominância do CO, porém, parece atuar dentro de certos limites, pois uma correlação significativa do teor de CO do solo com a classe 8 a $2 \mathrm{~mm}$ só foi obtida ao serem retirados da análise os dados de CO referentes aos extremos superior (floresta do Neossolo, 63,4g kg-1) e inferior (lavoura do Argissolo, 11,7g kg-1 $)(\%$ agregados $(8-2 \mathrm{~mm} ; \mathrm{T} 0)=0,4376$ x CO + 19,27; 0,977; $<<0,02 ; n=4)$, sugerindo um intervalo de maior influência do CO do solo na agregação entre 1,17 e $6,34 \mathrm{~g} \mathrm{~kg}^{-1}$, nas condições deste estudo.

Neste estudo, não foram verificadas correlações entre os teores de óxidos de $\mathrm{Fe}\left(\mathrm{Fe}_{\mathrm{d}}\right.$ e $\left.\mathrm{Fe} \mathrm{o}_{\mathrm{o}}\right)$ do solo e a distribuição de agregados, nem dos teores de óxidos de Fe nos agregados com a sua distribuição, concordando com DESHPAND et al. (1964) e BOOGARD (1983). A pequena variação nos teores dos óxidos de Fe nas amostras pode ser uma das causas, conforme discutido por DUIKER et al.(2003).

Analisando individualmente o comportamento da \% agregados das classes de tamanho de 8 a $2 \mathrm{~mm}$ e de 2 a $0,25 \mathrm{~mm}$, em função do tempo de agitação, o efeito das práticas agrícolas na diminuição da estabilidade foi claramente observado no Argissolo (Figura 1), onde tanto o uso floresta quanto o uso pastagem apresentaram maior \% agregados em relação ao uso lavoura, independentemente do tempo de agitação. Para o Neossolo (Figura 2), os usos floresta e pastagem somente apresentaram maior \% agregados em relação ao uso lavoura nos tempos 60 e 90min de agitação. Nos tempos iniciais de agitação (0 e 30min), para a classe de 8 a $2 \mathrm{~mm}$, o uso lavoura apresentou uma \% agregados intermediária entre o uso pastagem (maior) e o uso floresta (menor) e, na classe de 2 a 0,25mm, o uso lavoura apresentou uma maior \% de agregados em relação aos usos floresta e pastagem.

A alta \% agregados da classe de 8 a $2 \mathrm{~mm}$ verificada para o uso lavoura do Neossolo nos tempos 0 e 30min é o oposto do verificado para o Argissolo e ao comumente relatado na literatura, pois o preparo do solo aplicado a sistemas de cultivo como o convencional (uso lavoura) promove a destruição dos macroagregados, aumentando a quantidade de microagregados no solo (CARPENEDO \& MIELNICZUK, 1990; BRONICK \& LAL, 2005). Uma possível explicação disso pode ser a alta concentração de CO no solo encontrado nessa situação, sugerindo que essa concentração é fundamental para a resposta dos solos aos tipos de uso e sistemas de manejo.

Já a maior \% agregados verificada para a classe de 8 a $2 \mathrm{~mm}$ no uso pastagem do Neossolo aos 0 e 30min de agitação, em relação ao uso floresta, também verificada para esse uso no Argissolo (0min), evidencia a influência do sistema radicular desse tipo de vegetação, que, por ser mais densa, mais bem distribuída e por liberar uma grande quantidade de exudatos no solo, favorece as ligações dos pontos de contato entre partículas minerais e o contato entre os próprios agregados do solo, favorecendo a sua formação e estabilização no horizonte A(BRONICK \& LAL, 2005).

Teores de Carbono Orgânico (CO) e de Ferro ( $\mathrm{Fe}_{\mathrm{d}} \mathrm{e}$ $\mathrm{Fe}_{\mathrm{o}}$ ) nas classes de agregados do solo

Quanto aos teores de CO nas classes de agregados, observou-se que, tanto no Argissolo quanto no Neossolo (Figuras 1 e 2), ocorreu um maior teor de CO nos agregados (linhas cheias) que no solo (linha tracejada), independentemente do tempo de agitação e de uso. Se, por um lado, o carbono aumenta a estabilidade dos agregados, por outro, os agregados do solo, devido à proteção física, diminuem a taxa de decomposição dos resíduos orgânicos (SIX et al., 1998; BRONICK \& LAL, 2005), o que faz com que os teores de CO nos agregados variem diretamente com os teores de CO do solo.

Para a classe de 8 a $2 \mathrm{~mm}$, nos três usos do Neossolo e no uso floresta do Argissolo, ocorreu um aumento nos teores de CO nos agregados, que resistiram aos 30min de agitação. Uma hipótese para explicar esse resultado é a liberação da matéria orgânica particulada (MOP - Fração livre) que une os agregados menores, componentes dos agregados dessa classe (STEVENSON, 1994). Durante o procedimento de obtenção dos agregados para as análises químicas, a MOP não foi separada, sendo retida na peneira de $2 \mathrm{~mm}$ e contabilizada como carbono pertencente aos 
agregados da classe de 8 a $2 \mathrm{~mm}$ que resistiram à agitação.

Para a classe de 2 a $0,25 \mathrm{~mm}$, da mesma forma que para classe de 8 a $2 \mathrm{~mm}$, apesar de mais discreta, também se observou um acréscimo dos teores de CO nos agregados aos 30min de agitação nos usos floresta e pastagem do Argissolo e no uso pastagem do Neossolo, resultado que também poderia ser atribuído à liberação da MOP, sugerindo que os agregados dessas classes também estariam sendo formados por agregados da classe de 0,25 a $0,053 \mathrm{~mm}$, confirmandose, assim, mais um nível hierárquico entre as classes de agregados. SIX et al.(1998) também observaram uma expressiva quantidade de MOP liberada com a desagregação de macroagregados ( $>0,25 \mathrm{~mm}$ ) em solos de diversas características, sendo maior nos sistemas de manejo que preservaram o CO no solo (plantio direto e vegetação nativa), em relação ao sistema de cultivo convencional.

Além de um aumento nos teores de $\mathrm{CO}$ nos agregados que resistiram ao aumento da energia desagregante, também foi observada uma tendência de aumento nos teores de $\mathrm{Fe}_{\mathrm{d}}$ nos agregados que resistiram a 60 e 90 minutos de agitação em ambos os solos (Figura 1 e 2), o que permite inferir que, além dos teores de CO, os agregados mais estáveis também apresentam maiores teores de $\mathrm{Fe}_{\mathrm{d}}$. Para os teores de $\mathrm{Fe}_{\mathrm{o}}$, observou-se uma tendência de maiores teores nos agregados do que no solo. Além disso, observou-se que, nos agregados que resistiram a 90 min de agitação, os teores são menores que no solo. Isso pode estar sendo ocasionado pelos maiores teores de $\mathrm{CO}$ e $\mathrm{Fe}_{\mathrm{d}}$ neste tempo.

No Argissolo (Figura 1), os agregados da classe de 8 a $2 \mathrm{~mm}$ tenderam a apresentar maiores teores de $\mathrm{Fe}_{\mathrm{d}}$ e $\mathrm{Fe}_{\mathrm{o}}$ em relação aos agregados das outras classes, enquanto que, no Neossolo (Figura 2), ocorreu o oposto, exceto para os teores de $\mathrm{Fe}_{0}$ do uso lavoura (menor teor de CO). Este resultado provavelmente ocorre pela menor incorporação de CO na classe 8 a 2mm do Argissolo em relação ao Neossolo, mesmo não sendo possível uma observação mais concreta dessa situação devido à pequena produção de agregados na classe 8 a $2 \mathrm{~mm}$, nos usos pastagem e lavoura do Argissolo.

O comportamento da concentração de Fe nos agregados em função do tempo de agitação foi bimodal, isto é, observou-se picos de maior concentração de $\mathrm{Fe}_{\mathrm{o}}$ nos tempos 0 e 60min de agitação, o que provavelmente está relacionado com a hierarquia de agregados verificada nos solos. E esta última condiciona a liberação de MOP aos 30min e os maiores teores de $\mathrm{CO}$ e $\mathrm{Fe}_{\mathrm{d}}$ nos agregados aos $90 \mathrm{~min}$ de agitação, ocasionando, assim, os menores teores de $\mathrm{Fe}_{\mathrm{o}}$ aos 30 e $90 \mathrm{~min}$ de agitação. No entanto, como este comportamento também foi observado na classe de $8 \mathrm{a}$ $2 \mathrm{~mm}$ em todos os usos do Neossolo e no uso floresta do Argissolo, classe a qual não apresenta HA, ou, pelo menos, onde $T_{i}>P_{i}$, outros fatores além da presença de HA nos solos podem ter causado essa bimodalidade, como, uma associação entre a $\mathrm{CO}$ e Fe .

Assim, os resultados sugerem que o $\mathrm{CO}$ e as formas de ferro do solo expressam sua capacidade estabilizante em níveis diferentes de energia de desagregação (carbono até 30 minutos, $\mathrm{Fe}_{\text {o }}$ aos 60 e $\mathrm{Fe}_{\mathrm{d}}$ aos 90), bem como se distribuem de maneira diferente nos agregados dos dois solos e que, apesar de possuírem mecanismos de formação cujas taxas são maiores que aquelas de formação do solo, a estabilidade e a distribuição de agregados guardam relações com a evolução pedogenética do solo.

\section{CONCLUSÕES}

O Neossolo apresentou os maiores e o Argissolo os menores teores de CO do solo, independentemente do tipo de uso; e o uso floresta apresentou o maior e o uso lavoura o menor teor CO, independentemente do tipo de solo. Já os teores de $\mathrm{Fe}_{\mathrm{d}}$ e $\mathrm{Fe}$ foram muito similares entre os solos e usos, exceto para o uso pastagem, o qual apresentou os menores teores.

Os solos estudados apresentaram HA e essa se expressou mais no Neossolo, provavelmente devido ao seu maior teor de CO em relação ao Argissolo. No Argissolo, a \% agregados na classe de 8 a $2 \mathrm{~mm}$ foi floresta > pastagem > lavoura. No Neossolo, essa ordem somente foi verificada após $60 \mathrm{~min}$ de agitação, devido à intensa ação radicular no uso pastagem e ao alto teor de CO do uso lavoura.

Somente existiu correlação entre os teores de CO do solo e a distribuição de agregados e entre os teores de CO do solo e os teores de CO nos agregados. Além disso, os agregados mais estáveis (90min) tenderam a apresentar maiores teores de CO e $\mathrm{Fe}_{\mathrm{d}}$ e menores de $\mathrm{Fe}_{\mathrm{o}}$ que os menos estáveis (0min), e os resultados também indicam que a ação dos óxidos na agregação depende não somente de seus teores e tipos, mas também dos teores de CO existente nos solos.

\section{REFERÊNCIAS}

BUOL, S.W. et al. Soil genesis and classification. 2.ed. Ames: Iowa State University, 1997. 527p.

Ciência Rural, v.37, n.2, mar-abr, 2007. 
BAVER, L.D. et al. Soil structure, classification and genesis. In: BAVER, L.D.; GARDNER, W. Soil physics. 4.ed. New York: Jonh Wiley \& Sons, 1972. p.130-177.

BOOGARD, O.K. Iron oxide in relation to aggregation of soil particles. Acta Agricola Scand, v.23, p.257-260, 1983.

BRONICK, C.J.; LAL, R Soil strucuture and manegment: a review. Geoderma, v.124, p.3-22, 2005.

CARPENEDO V.; MIELNICZUK J. Estado de agregação e qualidade de agregados de Latossolos Roxos, submetidos a diferentes sistemas de manejo. Revista Brasileira de Ciência do Solo, v.14, p.99-105, 1990.

DESHPAND, T.L. et al. Role of iron oxides in the bonding of soil particles. Nature, v.201, p.107-108, 1964.

DEXTER, A.R. Advances in caracterization soil structure. Soil Tillage Research, v.11, p.199-238, 1988.

DUIKER, S.W. et al. Iron (hidr)oxide cristallinity effects on soil aggregation. Soil Science Society of America Journal, v.67, p.606-611, 2003.

ELLIOT. E.T. Aggregate structure and carbon, nitrogen, and phosporus in native and cultivated soils. Soil Science, v.50, p.627-633, 1986.

EMBRAPA. Centro Nacional de Pesquisa de solos. Sistema Brasileiro de Classificação de Solos. Brasília, 1999. 412p.

HADAS, A. Long-term tillage practice effect on soil aggregation modes and strength. Soil Science Society of America Journal, v.51, p.191-197, 1987.

HILLEL, D. Environmental soil physics. 3.ed. London: Academic, 1998. 771p.

HOLMGREN, G.G.S. A rapid citrate-dithionite extractable iron procedure. Soil Science Society of America Journal, v.31, p.210-211, 1967.

KEMPER, W.D.; CHEPIL, W.S. Size distribution of aggregates. In: BLACK C.A. Methods of soil analysis.
Part 1. Madison: Soil Science Society of América, 1965. p.495509.

KLAMT, E. et al. Solos do município de são João do Polesine: Características, classificação, distribuição geográfica e aptidão de uso. Santa Maria: UFSM, CCR, Departamento de solos, 1997. 93p.

MEHRA, O.P.; JACKSON, M.L. Iron oxides removal from soils and clays by a dithionite-citrate system buffered with sodium bicarbonate. Proceedings Clay and Clay Mineral Conference, v.7, p.317-327, 1960.

NELSON, D.W.; SOMMERS, L.E. Total carbon, organic carbon and organic matter. In: SPARKS, D.L. et al. Methods of soil analysis: chemical methods. Part 3. Madison: Soil Science Society of América, 1996. p.961-1010.

OADES J.M.; WATERS, A.G. Aggregates hierarchy in soils. Australian Journal of Soil Research, v.29, p.815-828, 1991.

SIX, J. et al. Aggregation and soil organic matter accumulation in cultiveted and native grassland soils. Soil Science Society American Journal, v.62, p.1367-1377, 1998.

SIX, J. et al. Soil structure and organic matter: I. distribution of aggregate-size classes and aggregate-associated carbon. Soil Science Society of America Journal, v.64, p.681-689, 2000.

SCHWERTMANN, U. Differiezerung der Eisienoxide des Bodens durch photochemische extraktion mit sauer Ammoniumoxalat-Lösung. Z Pflanzenernähr, v.105, p.194202, 1964.

SOIL SURVEY STAFF. Soil taxonomy. 6.ed. Department of Agriculture, USA. Soil Conservation Service, 1994. 305p.

STEVENSON, F.J. Humus chemestry: genesis, composition, reactions. 2.ed. New York: Jonh Wiley \& Sons, $1994.496 p$.

YEOMANS, J.C.; BREMNER, J.M. A rapid and precise method for routine determination of organic carbon in soil. Commun. In: Soil Science: Plant Analysis, 1988. p.1467-1476. 